\title{
INDÚSTRIA CULTURAL E O SISTEMA APOSTILADO: A LÓGICA DO CAPITALISMO
}

Carlos Eduardo de Souza Motta*

\begin{abstract}
RESUMO: O texto propõe uma reflexão sobre o sistema de ensino apostilado adotado em escolas e cursos preparatórios. A apostila é vista como um símbolo de eficiência e modernização, passando um conhecimento de maneira organizada, prática e racional, tendo como um único objetivo a aprovação no vestibular. $\mathrm{O}$ ensino apostilado compartimentaliza as informaçôes e faz o indivíduo perder a criticidade; notase, portanto, uma mercantilização e massificação do conhecimento, transformando o "ensino" em mais um produto da Indústria Cultural.

Palavras-chave: Indústria Cultural, Sistema de Ensino Apostilado, Comunicação de Massa e Educação
\end{abstract}

O sistema apostilado adotado em muitos cursos preparatórios e escolas começou a aparecer na década de 1950, com a alegação de ser mais prático, dinâmico e, principalmente, mais coerente com a nova "realidade" da educação brasileira. Atualmente, esta idéia não mudou e o sistema apostilado substituiu quase totalmente o livro didático, principalmente dentro da rede particular de ensino.

O discurso da modernização, ${ }^{1}$ um dos que mais justificam o uso de apostilas, é muito forte e sensibilizador, pois tal material é tido, também, como o mais viável economicamente. A propaganda envolvendo esse tipo de material pedagógico e a força dos slogans produzidos unificam idéias e atitudes-chave para o sucesso deste modelo. Para não cairmos nas teias do discurso da modernização, do mundo global e das novas tendências do mercado educacional, precisamos refletir sobre diversos aspectos: Como entender a educação em um contexto social e político? Quais são as intenções gerais dos modelos educacionais no Brasil? A quem os modelos realmente beneficiam? Como enfrentar o mito da globalização e o seu discurso modernizador dentro do universo educacional?

\footnotetext{
* Professor do Ensino Médio da rede particular de ensino (Poços de Caldas, MG), membro do Grupo de Estudos e Pesquisas: Indústria Cultural e Educação.E-mail: kakamotta@zipmail.com.br
} 
Tais questionamentos, de alguma maneira já correntes, estão sendo debatidos e estudados. A intenção aqui é colocar em pauta uma reflexão sobre o tema para que, com o passar do tempo, não deixemos os novosvelhos símbolos transformarem-se em "verdades". Tais símbolos são ideologicamente formados e assimilados pelo senso comum e servem, na sociedade capitalista, para ocultar a subordinação de uma classe em detrimento da outra.

Fazendo uma digressão, constata-se que, em nossa sociedade, ao falar em educação, devemos sempre nos reportar às doutrinas pedagógicas, que estariam relacionadas direta ou indiretamente à "realidade". Concretamente, os processos de ensino e aprendizagem far-se-ão presentes através de instituições específicas que irão transmitir, por meio de uma "doutrina pedagógica”, os valores das instituições: família, igreja, comunidade e escola são alguns exemplos.

O homem vive em sociedade e aprende com seu semelhante. Não podemos aceitar esta constatação sem olhá-la criticamente. $\mathrm{O}$ termo doutrina pedagógica pode soar como uma camisa de força. $\mathrm{O}$ indivíduo é um ser reflexivo que através das gerações não apenas reproduz os valores e as experiências das gerações passadas. A educação precisa ser vista não como uma mera reprodução, mas sim como algo libertador, dinâmico, com a finalidade até mesmo de colaborar em uma eventual mudança na estrutura social vigente. Não deve haver separação entre educação e vida. A vida é antes de tudo uma ação educativa. Como pensar o ato de educar de maneira livre e dinâmica? $\mathrm{O}$ ato educacional deve dar ao indivíduo as condiçōes necessárias para que este reflita sobre as experiências vividas e tentar ajudá-lo na ordenaçãao e na sistematização deste processo, tendo a escola todas as condições para estabelecer estas reflexões. Mas, como pensar em educação desvinculada de um processo maior?

A história recente de nossa sociedade vincula-se ao capitalismo, com a divisão social do trabalho e a diferenciação na posse e aquisição dos meios de produção.

Analisando a concepção de Bourdieu para a educação, Bárbara Freitag (1986) afirma que

O sistema educacional é visto como uma instituição que preenche duas funçôes estratégicas para a sociedade capitalista: a reprodução da cultura (...) e a reprodução da estrutura de classes. Uma das funções se manifesta no mundo das "representaçôes simbólicas" ou ideologia, a outra na própria realidade social. Ambas as funçōes estão intimamente interligadas, já que a função global do sistema educacional é garantir a reprodução das relações sociais da produção. 
Esta educação que reproduz a ideologia da classe dominante está voltada exclusivamente para o incremento da capacidade, entendida como o simples aprimoramento da força de trabalho. Este tipo educação, e porque não falar da escola, se transforma em uma verdadeira fábrica de mão-deobra, preocupando-se mais com as demandas mercadológicas do que com a obtenção do conhecimento. Este modelo negligencia o indivíduo e se preocupa com o rendimento qualitativo e quantitativo, necessário para cobrir a demanda do mercado na reprodução capitalista. Não se trata de desenvolvimento e, até mesmo, de capacitação para o trabalho, entendido democraticamente, isto é, com o objetivo de estender a aquisição dos saberes intelectuais, materiais e culturais igualitariamente para todos.

Ao desvendar a estrutura capitalista e sua relação com a educação, precisamos nos aprofundar nos aspectos ideológicos. Estes revelam a perpetuação da lógica capitalista. Louis Althusser (1987), pela primeira vez, caracteriza a escola como um "aparelho ideológico do Estado". Para ele, a escola terá a função de reproduzir as relaçōes materiais e sociais da produção. A escola, além de simplesmente trabalhar a serviço do mercado, transforma-se em fábrica de mão-de-obra, atuando em um nível maior, o ideológico. De acordo com Althusser, existe todo um trabalho para que o indivíduo se sujeite a regras previamente estabelecidas. Através da transmissão do conhecimento, pela palavra, é que a escola executará este papel. Em sua concepção, a escola não cria a divisão de classe, mais vai contribuir para sua reprodução. Nesta roda viva, o indivíduo indiretamente aceita sua condição de classe, pois a própria educação, ideologicamente forjada, prepara-o para o mercado e gera no indivíduo uma sensação de eficiência, de potencial, de utilidade.

Porém, se a escola tem a sua participação no processo de reprodução social, ela não é a única instituição responsável por tal reprodução. A começar pelas questôes macro-econômicas da qual fazem parte outros fatores de ordem política, social e cultural.

Contrariamente à visão pessimista de que todas as instituiçôes de nossa sociedade estão reproduzindo a lógica do capitalismo e as estratégias de dominação das elites, Gramsci (apud Freitag, 1986) desenvolve a idéia de "contra-hegemonia". A escola como instituição pode iniciar um movimento contra-hegemônico, assumindo um papel estratégico de mudança. Segundo Gramsci, o Estado, não sendo autoritário, permite que a sociedade seja um campo aberto para circulação de ideologias. ${ }^{2}$ Logo, se existe uma ideologia dominante, também pode existir uma contra-ideologia que venha combater e servir para a libertação das classes subjugadas. Se a escola reproduz 
uma educação que se identifica e justifica uma certa relação de dominação, ela também pode criar condições de libertação ou ao menos estabelecer a crítica, livrando o indivíduo dos descaminhos do senso-comum e da fragmentação que deformam o desenvolvimento cognitivo, afetivo, social e cultural dos alunos.

O conhecimento apostilado, porém, produzido em verdadeiras "fábricas do saber" potencializa a "(re)produção" de indivíduos massificados, prontos à adequação social que, atualmente, tem como um de seus principais objetivos o consumo. Sem este, não há capitalismo.

Quais seriam, pois, as saídas? Primeiramente, seria necessário estabelecermos uma crítica desmistificadora desse modelo educacional. Para tanto, voltemos um pouco à história recente da nossa educação. Não se pretende, aqui, detalhar os modelos educacionais adotados, mas, sim, traçar um painel geral para entendermos qual é a lógica da educação no Brasil e vermos que a apostila é um símbolo de modernização diretamente vinculado ao ideal de progresso, eficiência e dinamismo.

A idéia de progresso econômico, de nação independente, sempre esteve presente no imaginário da nação brasileira. ${ }^{3} \mathrm{Na}$ independência, na instauração da República e no atual governo, o objetivo sempre foi o de inserir o país no rol das economias desenvolvidas.

Tendo como ponto de partida a década de 1950, no governo de Juscelino Kubitschek, notamos que a visão de progresso estava intimamente ligada ao desenvolvimento industrial. A nação dependia, segundo a ótica do governo, do investimento na industrialização para alcançar a modernização. O Plano de Metas vai pensar a educação como um meio de aprimorar o desenvolvimento industrial e consolidar o capitalismo brasileiro. A educação é claramente pensada como formação voltada para atender as demandas do mercado. A mão-de-obra não qualificada era encarada como um risco para o desenvolvimento econômico.

Nos governos militares pós-1964, percebemos a mesma vinculação da educação ao desenvolvimento capitalista e, também, toda uma ideologia forjada para a aceitação do regime não democrático que era propagandeada pelo discurso de que as ações governamentais iriam beneficiar a mobilidade social. Partia-se do pressuposto de que naquela sociedade capitalista em "desenvolvimento" todos teriam reais possibilidades de crescimento econômico e social. O objetivo do ensino era instrumentalizar e adequar o indivíduo para o mercado, visando o aumento da capacidade produtiva. Esta lógica aparece nitidamente no governo Médici. Segundo Lewin (1985), 
(...) a educação passa por uma intensa metamorfose: a ser protagonista essencial na equação operada pelo Estado para controlar eficientemente o processo político de seu desenvolvimento capitalista. Na medida em que a segurança é definida como condição prévia para o desenvolvimento, esperase da educação o desempenho de papéis reforçativos desse postulado, devendo preencher, para tanto, três funções básicas em sua nova atribuição de produtora de recursos humanos: I - a educação como segurança do sistema econômico capitalista. II - a educação como segurança da sociedade capitalista. III - a educação como segurança do progresso nacional.

Caminhando em direção aos anos 80, com o processo de abertura política, a educação estaria a serviço da cidadania, da participação política e do desenvolvimento da justiça. Estas idéias, porém, não se concretizaram e, mais uma vez, a educação ficaria vinculada ao processo produtivo, sendo sua "eficácia" comprovada apenas quando esta concretizasse a relação educação-desenvolvimento econômico.

Na década de 1990, um novo dado pode ser acrescentado nesta estrutura educacional que privilegia o capital. O discurso da globalização vincula a educação à racionalização administrativa e à eficiência produtiva, para que a nação possa competir em um mercado internacional cada vez mais dinâmico e competitivo.

O discurso de um mundo e de um mercado global atinge e transforma os objetivos educacionais. Nos dias atuais, propagandeia-se que nossa sociedade muda velozmente e que o indivíduo precisa estar adaptado a estas mudanças. Note-se que o importante, agora, é responder às necessidades do mercado que exige profissionais dinâmicos, criativos, capazes de se adaptar rapidamente a novas situaçôes, informados e informatizados. Para tanto, a escola priorizou a aquisição de um grande número de informações (destarte seu objetivo desde os enciclopedistas), porém, agora, com critérios de utilidade, facilidade e rapidez.

Mas o que seriam informações úteis? Se voltarmos a Kant, Comte e Bacon, veremos que o conhecimento, a ciência deveria superar os estágios considerados menos desenvolvidos da metafísica e da teologia Para a sociedade atual, a resposta é a adaptação introjetada pela "sapiência" da Indústria Cultural. Ela mostra aos indivíduos o que realmente é útil, "racionalizando" e padronizando as ações. Dentro deste universo, o indivíduo perde a criticidade e a produção cultural torna-se mercadoria. Perdendo o poder reflexivo, a sociedade fica a mercê dos grupos que monopolizam as informações. Por sua vez, a educação também se transforma em um produto da Indústria Cultural, uma vez mais reproduzindo a ideologia dominante. Esta, mesmo em sociedades democráticas, como tão bem demonstrou Aléxis 
de Tocqueville em Democracia na América, reforça seu poder sobre os indivíduos tutelados.

Zeloso guardião de seu poder, o Estado, nas palavras de M. Tragtemberg, é o grande organizador da hegemonia, no sentido gramsciano do termo, controlando, através de licenças, os instrumentos de reprodução simbólica. Desativando a política e eliminando a opinião pública com capacidade de opor-se, ele, por meio da comunicação de massa, reforça o controle social. Ou seja, sob uma fachada democrática, o Estado no século XX realiza a "democracia totalitária" enunciada por Tocqueville no século passado (Prefácio da obra de Marcondes Filho, 1986).

É nesse sentido que o sistema de ensino apostilado contribui para a tutela e a adaptação social. Ele é mais uma mercadoria inserida no contexto da Indústria Cultural. Pela fragmentação do conhecimento, compartimentaliza o saber. O conteúdo do ensino é dividido em cadernos, que por sua vez são subdivididos em matérias, com aulas seguindo uma numeração durante o ano letivo. As aulas são esquemáticas ou com textos explicativos que não dão margem a analogias e, conseqüentemente, a uma discussão mais aprofundada. Os exercícios propostos ao final de cada aula servem apenas para testar o conhecimento "dito mais importante", segundo a perspectiva do sistema. $\mathrm{O}$ mais grave é a impressão que as apostilas passam de que esta maneira de organizar o conhecimento é mais "prática", dando a sensação de que todo o conhecimento a ser atingindo está contido naquelas poucas páginas.

No discurso, os elaboradores das apostilas argumentam que elas são apenas um meio para que o professor possa discutir, debater e fazer analogias sobre o assunto ministrado. Mas, como "subverter" sua lógica quando o número total de aulas vencido é considerado condição para o êxito do professor e da aprovação no vestibular por parte do aluno? $\mathrm{O}$ aluno influenciado, e porque não dizer manipulado pelas propagandas dos cursos preparatórios, acredita no produto que comprou e seu desempenho estará vinculado ao bom funcionamento do material. Este, então, cumpre a dupla função de massificar o professor e o aluno. Como observa Zuin (1995, p. 153):

Por detrás do processo de massificação do produto vinculado pela Indústria Cultural, pode-se vincular a promessa de que a produção cultural, enquanto patrimônio universal da humanidade, seria reapropriado por todos. Não obstante, o que efetivamente ocorre é a (pseudo) redemocratização destes mesmos produtos. 
$\mathrm{Na}$ escola, o sistema apostilado, como mais uma mercadoria inserida no contexto da Indústria Cultural, promete oferecer um ensino organizado, prático e racional. Mas, fragmentando o conhecimento, incapacita o indivíduo de compreendê-lo de maneira global, incluindo causas, processos, conseqüências, contextos etc. A quebra da unidade impede a ação reflexiva e transforma-se em instrumento de dominação. Reproduz a ideologia de setores privados e do próprio Estado, preparando o indivíduo quase que exclusivamente para o vestibular, afastando-o da possibilidade de um ensino e de uma educação emancipadores, bem como do conhecimento, da aquisição e do usufruto da cultura. Mais do que isso, impede-o de refletir sobre sua condição de cidadão e de optar com maior liberdade por seu destino.

\section{Notas}

1. Sobre a questão da modernização, Raimundo Faoro (1992), em A questão nacional, faz uma distinção entre os conceitos de modernização e de modernidade: "Em vez de buscar a modernidade, o Brasil padece de ímpetos de modernização, através dos quais se tenta queimar etapas do processo de desenvolvimento Uma nova modernização sepulta a anterior e nenhuma consegue fazer com que o País encontre o caminho para o desenvolvimento. Impostas por elites pseudodissidentes em favor de seus interesses, essas modernizações mantêm a maioria da população alijada de benefícios sociais elementares".

2. A idéia de Gramsci sobre "contra hegemonia" foi analisada por Bárbara Freitag em Escola, Estado e Sociedade (1986, p. 38).

3. Sobre os ideais e o imaginário brasileiros, sempre descolados das condições reais de realização, ver Renato Ortiz (1989).

\section{CULTURAL INDUSTRY AND THE BOOKLET LEARNSHIP SYSTEM:}

\section{THE CAPITALIST LOGIC}

ABSTRACT: The text suggest a reflection about the booklet learnship system adopted in some private schools and preparatory courses. The "apostila" is seems as a symbol of efficience and modernization, transmitting knowledge in a tidy way, practical and rational, with the only aim of vest approval (entrance examination). The booklet learnship system shon the information in "parts" and makes the person loose his power of criticism, it is noticed however, a kind of "trade" and mass production of knowledge, transforming the "teaching" process in just another cultural industry.

Key words: Cultural Industry, Booklet Learnship System, Mass Communication and Education. 
Referências bibliográficas

ALTHUSSER, Louis. Ideologia e aparelhos ideológicos do Estado. Rio de Janeiro: Graal, 1987.

FAORO, R. A questão nacional. Estudos Avançados, no 14, vol. 6, São Paulo: USP, Jan./Abr. 1992.

FREITAG, B. Escola, Estado e Sociedade. São Paulo: Editora Moraes, 1986.

LEWIN, H. Educação e Desenvolvimento no Planejamento Governamental Brasileiro. Em Aberto, no 27, ano 4, Brasília, jul./set. 1985.

MARCONDES FILHO, Ciro. O Capital da notícia: Jornalismo como produção social da segunda natureza. São Paulo: Ática, 1986.

ORTIZ, R. A moderna tradição brasileira - Cultura brasileira e Indústria Cultural. $3^{\mathrm{a}}$ ed. São Paulo: Brasiliense, 1991.

TOCQUeVIlle, A de. Democracia na América. Trad. de J.A.G. Albuquerque. $3^{a}$ ed., São Paulo: Abril Cultural, 1985.

ZUIN, A.A.S. "Seduçôes e simulacros - Consideraçōes sobre Indústria Cultural e os paradigmas da resistência e da reprodução em educaçáo". In: Pucci, B (org.). Teoria Crítica e Educação: A questão da formação cultural na Escola de Frankfurt. Petrópolis: Vozes/São Carlos: EDUFSCar, 1994, p.153.

. Indústria Cultural Educação: O novo canto da sereia. Campinas: Autores Associados, 1999. 